\title{
Correction to: Youth-onset type 2 diabetes: translating epidemiology into clinical trials
}

\author{
Laura Pyle $^{1,2} \cdot$ Megan M. Kelsey ${ }^{1}$ \\ Published online: 26 July 2021 \\ (C) Springer-Verlag GmbH Germany, part of Springer Nature 2021
}

\section{Correction to: Diabetologia \\ https://doi.org/10.1007/s00125-021-05480-w}

SEARCH was incorrectly described as a randomised, not observational, study. The corrected text box is reproduced here.
The online version of the original article can be found at https://doi.org/ 10.1007/s00125-021-05480-w

Megan M. Kelsey

megan.kelsey@childrenscolorado.org

1 Section of Paediatric Endocrinology, University of Colorado School of Medicine, Aurora, CO, USA

2 Department of Biostatistics and Informatics, Colorado School of Public Health, Aurora, CO, USA

\section{Major trials/studies of treatment for youth with type 2 diabetes}

\section{TODAY [14]}

- $N=699$ participants, 10-17 years of age, with type 2 diabetes duration $<2$ years and $\mathrm{BMI} \geq 85$ th percentile.

- Participants were randomised to metformin alone, metformin+rosiglitazone or metformin+lifestyle modification, over a study period of 2-6 years.

- In total, $45.6 \%$ reached the primary outcome of prolonged loss of glycaemic control. Once participants reached the primary outcome, metformin was continued, rosiglitazone (if present) discontinued and insulin initiated. Metformin+insulin was ineffective in preventing beta cell deterioration.

\section{RISE [15]}

- $N=91$ participants, $10-19$ years of age, with prediabetes or new-onset type 2 diabetes.

- Participants were randomised to insulin glargine for 3 months followed by metformin for 9 months or metformin for 12 months and followed over 15 months.

- Metformintinsulin was ineffective in preventing beta cell deterioration.

\section{SEARCH [27]}

- $N=474$ participants, $10-20$ years of age.

- Observational only; usual care given by diabetes provider. Some participants received more extensive testing (e.g. retinal photography, vascular measurements; study ongoing).

- After 7 years of follow-up, only 35\% met glycaemic targets $\left(\mathrm{HbA}_{1 \mathrm{c}}<53.0 \mathrm{mmol} / \mathrm{mol}[<7 \%]\right)$.

Publisher's note Springer Nature remains neutral with regard to jurisdictional claims in published maps and institutional affiliations. 